\title{
Optimal hedging using both regular and weather derivatives
}

\author{
Augusto Castillo* \\ Escuela de Negocios, \\ Universidad Adolfo Ibáñez, \\ Avenida Diagonal las Torres 2700, \\ oficina 513-C, \\ Santiago, Chile \\ Email: augusto.castillo@uai.cl \\ *Corresponding author
}

\section{Rafael Aguila}

Escuela de Administración,

Pontificia Universidad Católica de Chile,

Avenida Vicuña Mackenna 4860,

Santiago, Chile

Email: raguilab@uc.cl

\begin{abstract}
This paper analyses how to achieve optimal hedging of a cash flow to be received at a future date $\mathrm{T}$, when facing price risk, cost and quantity uncertainty. We explore and compare the case where the only instrument available to hedge is a regular forward contract (to hedge the price uncertainty), the case where we only have access to a linear-type weather derivative to hedge quantity, and the case where both types of contracts are available. A closed form solution for both the optimal hedging strategies and the quality of the hedging under each scenario are identified. We show how to obtain the optimal hedging strategies through linear regressions. Then, by using simulations, we explore how the results critically depend on some key factors such as the volatility of some stochastic variables considered and the degree of correlation among some of the variables considered.
\end{abstract}

Keywords: risk management; hedging; quantity uncertainty; weather derivatives.

Reference to this paper should be made as follows: Castillo, A. and Aguila, R. (2017) 'Optimal hedging using both regular and weather derivatives', Int. J. Bonds and Derivatives, Vol. 3, No. 1, pp.1-20.

Biographical notes: Augusto Castillo received his MBA, MA in Economics and $\mathrm{PhD}$ in Finance from UCLA. He is currently a Professor in Finance at the Business School of Universidad Adolfo Ibanez in Chile.

Rafael Aguila received his Master in Mathematical Statistics from CIENES-OEA. He is currently a Professor in Statistics and Numerical Methods at the Business School of the Pontifical Catholic University of Chile. 


\section{Introduction}

Firms face uncertainty in their future cash flows due to the interaction of stochastic variables such as prices, costs and level of production or sales. Those companies sometimes have access to regular hedging instruments such as forwards, futures or options, which are usually designed to take care of the uncertainty in prices. In the last years a new kind of hedging instruments (weather derivatives) has developed. These weather derivatives are contracts that offer a payment conditional on the performance of a weather variable such as temperature or rain for example. In this paper we explore how weather derivatives can improve the hedging of a firm, in particular if there is a strong correlation between the cash flow of the company and the weather variable defined as the underlying asset in the weather derivative contract.

There is evidence that firms hedge their cash flows. Previous research on why companies hedge, such as the ones performed by Smith and Stulz (1985), Bessembinder (1991), Froot et al. (1993) and Mello and Parsons (1995) have identified the desires to minimisation of the variance of future cash flows, the reduction of the volatility of taxable income, the desire to reduce dispersion of accounting earnings and the hope of being able to avoid financial distress as the main reasons for hedging. Other authors such as Neuberger (1999) assume that the desire for hedging comes from risk averse agents hoping to maximise their expected utility.

The use of forward or futures contracts to hedge against price and quantity risk works less than perfectly in the real world for several reasons: First, the variable we want to hedge from may not be the same as the variable considered in the futures contracts available in the market. In this case the quality of the hedge will critically depend on how closely correlated are those two variables ${ }^{1}$. This point has been developed in all the major derivatives and risk management textbooks. See for example, Duffie (1989), Stulz (2003) or Hull (2008). A recent paper by Basak and Chabakauri (2012) gives new insights on how to solve this problem through different techniques.

Second, the date of expiration or maturity of the future or forward contracts available to perform the hedging may not coincide exactly with the particular date in the future we will receive the foreign currency. This could happen for example if there are only short-term futures contracts available to hedge against long-term exchange rate exposure or if there are long-term futures contracts to hedge against short-term exchange rate exposure. This problem has been analysed among others by Brennan and Crew (1997), Neuberger (1999), Schwartz (1997), Broll et al. (1999), Castillo and Lefort (2003) and Castillo et al. (2012).

A third reason for hedging to work less than perfectly will arise if there is uncertainty regarding the quantity of production and/or selling. This problem has been analysed by authors such as Rolfo (1980), Newbery and Stiglitz (1981), Kamgaing (1989), Kerkvliet and Moffett (1991), Moschini and Lapan (1995), Wong (2003), Näsäkkälä and Keppo (2005), Castillo and Aguila (2008), Castillo et al. (2012), Frestad (2009), Oum and Orem (2010) and Korn (2010). None of these papers consider the availability of derivatives contracts as tools to hedge the cash flows of the companies.

Weather derivatives are relatively new. They start to develop in the 1990s. The most common weather derivatives are the ones related to either temperature or precipitations or snowfall at a specific geographic location. Temperature derivatives, for example, typically try to address losses caused by either too hot or too cold weather conditions. There are both over the counter and standardised exchange traded contracts. In each case, 
the exposition to basis risk resulting from the non-perfect correlation between the weather index used in the contract and the cash flow the investor is trying to hedge is an important concern for the user of these contracts.

Richards et al. (2004) are among the first studies that formalise how to use and price weather derivatives. Recent contributions on how to hedge with weather derivatives can be found in Golden et al. (2007), Torriani et al. (2008) and Manfredo and Richards (2009).

Golden et al. (2007) reviews the effectiveness of both linear (using forwards and futures) and nonlinear (using options) hedging strategies. They also compare the use of standardised exchange traded derivatives and custom tailored OTC derivatives and their effectiveness to decrease basis risk and credit risk. Using the mean-variance utility framework they derive optimal hedging strategies and use simulation to compare. Torriani et al. (2008) develop a hedging strategy using rain derivatives to cope with grain maize production in Switzerland. The effectiveness of the hedging was evaluated on the basis of a quantile-based risk measure of the profit distribution, i.e., the value at risk measure, as an alternative to the risk preference and utility functions used by others. Manfredo and Richards (2009) explore the fact that when using weather derivatives to cope with volumetric risk, risk managers often face unique basis risks arising from both the choice of the weather station where a derivatives contract is written, as well as the relationship between the hedged volume and the underlying weather index. They show that the use of nonlinear weather derivatives can be particularly helpful to minimise both sources of basis risk.

Our study analyses how to obtain an optimal hedging strategy when facing price, costs and quantity uncertainty, if both regular and weather derivatives are available. We analyse how both the optimal hedging strategy and also the quality of that hedging depends critically of parameters such as the volatilities of some of the stochastic variables considered and the correlations among some of those stochastic variables. We assume both the absence of transactions costs and also that the futures contracts available are infinitely divisible. These are standard assumptions in the cited literature.

This paper is organised as follows. In Section 2, the hedging problem faced by the firm is described and the optimal analytical solution is presented, under two different scenarios. The first one assumes that the company has only access to weather linear-type derivative contracts to hedge the future cash flow. The second one assumes that both regular and weather derivatives are available. Some particular cases are also presented here. Section 3 reports the implementation of the optimal hedging strategies described in Section 2 to a particular case and explores how efficient those optimal hedging strategies are under a series of different scenarios. Section 4 presents the main conclusions of the paper.

\section{The cash flow hedging model}

Let us assume that there is a company that is expecting to generate a certain cash flow, $T$ periods from now. We will suppose that the firm is facing three sources of uncertainty, which are the price of the product to be sold $\left(\tilde{P}_{T}\right)$, the per-unit cost of production $\left(\tilde{C}_{T}\right)$, and the level of production in physical units $\left(\tilde{Q}_{T}\right)$. The cash flow generated by the company if no derivatives are used to hedge will be described by the following equation: 


$$
\widetilde{C F}_{T}^{N H}=\tilde{P}_{T} \cdot \tilde{Q}_{T}-\tilde{C}_{T} \cdot \tilde{Q}_{T}
$$

\subsection{Only weather derivatives are available to hedge}

If we assume that only weather derivatives are available to hedge the cash flow, the following expression would represent the total cash flow that the company would generate at time $\mathrm{T}$ once the hedging strategy has been implemented.

$$
\widetilde{C F}_{T}^{H}=\widetilde{C F}_{T}^{N H}+G \cdot\left(\tilde{q}_{T}-N\right)
$$

where $N$ is the strike price in a forward-type weather derivative, $\tilde{q}_{T}$ represents the observed level for the weather underlying variable, and $G$ corresponds to the number of positions taken in the weather derivative. The variance of the cash flow we want to minimise can be written as:

$$
\operatorname{Var}\left(\widetilde{C F}_{T}^{H}\right)=\operatorname{Var}\left(\tilde{q}_{T}\right) \cdot G^{2}+2 \operatorname{Cov}\left(\widetilde{C F}_{T}^{N H}, \tilde{q}_{T}\right) \cdot G+\operatorname{Var}\left(\widetilde{C F}_{T}^{N H}\right)
$$

The optimal hedging strategy, defined as the value of $G$ that minimises the cash flow variance described in equation (3) would be represented by:

$$
G_{o p t}=-\frac{\operatorname{Cov}\left(\widetilde{C F}_{T}^{N H}, \tilde{q}_{T}\right)}{\operatorname{Var}\left(\tilde{q}_{T}\right)}
$$

Once the company has implemented the optimal hedging strategy described here the level of maximum efficiency, defined as the proportion of the total cash flow variance that will be reduced by hedging, can be computed by equation (5).

$$
\text { Max_Efficiency }=\frac{\operatorname{Cov}^{2}\left(\widetilde{C F}_{T}^{N H}, \tilde{q}_{T}\right)}{\operatorname{Var}\left(\widetilde{C F}_{T}^{N H}\right)_{\operatorname{Var}}\left(\tilde{q}_{T}\right)}
$$

It is interesting to notice that we can obtain the same optimal hedging strategy by running an OLS regression with $\widetilde{C F}_{T}^{N H}$ as the dependent variable and $\tilde{q}_{T}$ as the independent variable, as shown by equation (6).

$$
\widetilde{C F}_{T}^{N H}=\beta_{0}+\beta_{1} * \tilde{q}_{T}+\tilde{e}_{T}
$$

Solving by OLS we get the following expression:

$$
\hat{\beta}=\frac{\operatorname{Cov}\left(\widetilde{C F}_{T}^{N H}, \tilde{q}_{T}\right)}{\operatorname{Var}\left(\tilde{q}_{T}\right)}=-G_{o p t}
$$

And the maximum efficiency to be reached by the optimal hedging strategy corresponds to the determination coefficient $\left(\mathrm{R}^{2}\right)$ of the described regression. 


\subsection{Both regular and weather derivatives are available to hedge}

If we assume that the firm hedges through both regular and weather derivatives, the following expression represents the total cash flow that the company would generate at time $T$ :

$$
\widetilde{C F}_{T}^{H}=\widetilde{C F}_{T}^{N H}+H \cdot\left(\tilde{P}_{T}-K\right)+G \cdot\left(\tilde{q}_{T}-N\right)
$$

where $K$ is the forward price in a regular forward contract over the company's product, $H$ represents the number of positions taken in those forward contracts, $N$ is the strike price in a forward-type weather derivative, $\tilde{q}_{T}$ represents the observed level for the weather underlying variable, and $G$ corresponds to the number of positions taken in the weather derivative. The variance of the cash flow we want to minimise can be written as:

$$
\begin{aligned}
\operatorname{Var}\left(\widetilde{C F}_{T}^{H}\right)= & \operatorname{Var}\left(\widetilde{C F}_{T}^{N H}\right)+H^{2} \cdot\left(\tilde{P}_{T}\right)+G^{2} \cdot \operatorname{Var}\left(\tilde{q}_{T}\right)+2 \cdot H \cdot \operatorname{Cov}\left(\widetilde{C F}_{T}^{N H}, \tilde{P}_{T}\right) \\
& +2 \cdot G \cdot \operatorname{Cov}\left(\widetilde{C F}_{T}^{N H}, q_{T}\right)+2 \cdot H \cdot G \cdot \operatorname{Cov}\left(\tilde{P}_{T}, \tilde{q}_{T}\right)
\end{aligned}
$$

By minimising the variance of the cash flow we obtain the values of parameters $H$ and $G$, which represent the optimal hedging strategy for the company, defined as the number and the type of positions to be taken in both the regular derivatives contract available $(H)$ and the weather derivatives contract available $(G)$.

$$
\begin{aligned}
H_{o p t} & =\frac{\operatorname{Cov}\left(\widetilde{C F}_{T}^{N H}, \tilde{q}_{T}\right) \cdot \operatorname{Cov}\left(\tilde{P}_{T}, \tilde{q}_{T}\right)-\operatorname{Cov}\left(\widetilde{C F}_{T}^{N H}, \tilde{P}_{T}\right) \cdot \operatorname{Var}\left(\tilde{q}_{T}\right)}{\operatorname{Var}\left(\tilde{P}_{T}\right) \cdot \operatorname{Var}\left(\tilde{q}_{T}\right)\left(1-\operatorname{Corr}^{2}\left(\tilde{P}_{T}, \tilde{q}_{T}\right)\right)} \\
G_{o p t} & =\frac{\operatorname{Cov}\left(C F_{T}^{N H}, P_{T}\right) \cdot \operatorname{Cov}\left(\tilde{P}_{T}, \tilde{q}_{T}\right)-\operatorname{Cov}\left(\widetilde{C F}_{T}^{N H}\right) \cdot \operatorname{Var}\left(\tilde{P}_{T}\right)}{\operatorname{Var}\left(\tilde{P}_{T}\right) \cdot \operatorname{Var}\left(\tilde{q}_{T}\right)\left(1-\operatorname{Corr}^{2}\left(\tilde{P}_{T}, \tilde{q}_{T}\right)\right)}
\end{aligned}
$$

It is interesting to notice that if we consider the OLS regression described by equation (12), then the coefficients of the regression $-\beta_{1}$ and $-\beta_{2}$ represent the optimal hedging strategy (they are basically $H$ and $G$ ), and the determination coefficient $\left(\mathrm{R}^{2}\right)$ of the regression represents the maximum hedging efficiency that can be reached implementing those optimal strategies.

$$
E\left(\widetilde{C F}_{T}^{N H} / \tilde{P}_{T}, \tilde{q}_{T}\right)=\beta_{0}+\beta_{1} \cdot \tilde{P}_{T}+\beta_{2} \cdot \tilde{q}_{T}
$$

It is interesting to notice that if all the stochastic variables are independent (with the only exception of $\tilde{Q}_{T}$ and $\tilde{q}_{T}$ ) then the optimal hedging strategy described by equations (10) and (11) would become:

$$
H_{o p t}=-\frac{\operatorname{Var}\left(\tilde{P}_{T}\right) \cdot E\left(\tilde{Q}_{T}\right)}{\operatorname{Var}\left(\tilde{P}_{T}\right)}=-E\left(\tilde{Q}_{T}\right)
$$




$$
G_{\text {opt }}=-\frac{\operatorname{Cov}\left(\tilde{Q}_{T}, \tilde{q}_{T}\right)}{\operatorname{Var}\left(\tilde{q}_{T}\right)} \cdot\left[E\left(\tilde{P}_{T}-\tilde{C}_{T}\right)\right]
$$

As it can be observed from equation (13) the optimal hedging strategy with regular forward contracts considers taking a number of short positions in that contract equivalent to the expected number of long positions (or production level) in the final product of the company. The expression from equation (14) represents the optimal hedging strategy regarding the number of positions in the weather derivative. It is interesting how this expression would further simplify if we are able to find a derivative $\tilde{q}_{T}$ that is positively and perfectly correlated to production level $\tilde{Q}_{T}$ (let us suppose for example that $\left.\tilde{q}_{T}=a+b * \tilde{Q}_{T}\right)$. In that case the optimal weather derivative strategy would become:

$$
G_{o p t}=-\frac{E\left(\tilde{P}_{T}-\tilde{C}_{T}\right)}{b}
$$

\section{Implementing the optimal hedging strategy.}

\subsection{Assuming $\tilde{P}_{T}$ and $\tilde{Q}_{T}$ are not correlated}

In this section, the model described previously is implemented. We assume we have a company trying to hedge against the volatility of the cash flow of next period, and having access to only a regular derivative (Tables A), having access to only a weather derivative (Tables B), or having access to both types of derivatives (Tables C). On each table, section A shows the inputs required to implement the methodology and section B contains the results of implementing $\mathrm{it}^{2}$.

Tables 1A to 1C show the result of applying the optimal hedging methodology to different scenarios where the correlation between $\tilde{Q}_{T}$ and $\tilde{q}_{T}$ changes from 0.2 to 1.0. All the other stochastic variables (and in particular $\tilde{P}_{T}$ and $\tilde{Q}_{T}$ ) are assumed to be independent. The assumptions regarding volatility of the variables are described on each table.

Section B of Tables 1A to $1 \mathrm{C}$ presents the results of the optimal hedging policies and maximum efficiency to be reached under each scenario. In Table 1A, we appreciate how the quality of the hedging does not change when the correlation between $\tilde{Q}_{T}$ and $\tilde{q}_{T}$ increases and only regular derivatives are used. In Table 1B, we observe how the quality of the hedging using only weather derivatives increases as the degree of correlation between $\tilde{Q}_{T}$ and $\tilde{q}_{T}$ increases. In Table 1C, we appreciate how when both derivatives are used the quality of the hedging increases as the correlation between $\tilde{Q}_{T}$ and $\tilde{q}_{T}$ increases. Regarding the hedging policies we appreciate how the hedging level in the regular derivative does not change (significantly) across different correlations for $\tilde{Q}_{T}$ and $\tilde{q}_{T}$. In all the cases considered in Tables $1 \mathrm{~A}$ and $1 \mathrm{C}$, it remains equal to $-C\left(\tilde{Q}_{T}\right)$, as could be predicted from our equation (20), and how the level in weather derivatives increases as the correlation of $\tilde{Q}_{T}$ and $\tilde{q}_{T}$ increases, as could be deduced from our 
equation (21), where $G$ is a direct function of $\operatorname{Cov}\left(\tilde{Q}_{T}, \tilde{q}_{T}\right)$. In all cases the hedging strategies have a negative sign describing short positions in both derivatives, to hedge the long position in the product of the company.

Table 1A Changing the correlation between $\mathrm{Q}$ and $\mathrm{q}$ if only regular derivatives are available

\begin{tabular}{|c|c|c|c|c|c|}
\hline \multicolumn{6}{|c|}{ Section A: inputs } \\
\hline Inputs & Scenario 1 & Scenario 2 & Scenario 3 & Scenario 4 & Scenario 5 \\
\hline $\mathrm{E}(\mathrm{P})$ & 100 & 100 & 100 & 100 & 100 \\
\hline $\mathrm{E}(\mathrm{Q})$ & 100 & 100 & 100 & 100 & 100 \\
\hline $\mathrm{E}(\mathrm{C})$ & 60 & 60 & 60 & 60 & 60 \\
\hline$E(q)$ & 0 & 0 & 0 & 0 & 0 \\
\hline $\mathrm{SD}(\mathrm{P})$ & 15 & 15 & 15 & 15 & 15 \\
\hline $\mathrm{SD}(\mathrm{Q})$ & 25 & 25 & 25 & 25 & 25 \\
\hline $\mathrm{SD}(\mathrm{C})$ & 10 & 10 & 10 & 10 & 10 \\
\hline $\mathrm{SD}(\mathrm{q})$ & 1 & 1 & 1 & 1 & 1 \\
\hline $\operatorname{corr}(\mathrm{P}, \mathrm{Q})$ & 0.00 & 0.00 & 0.00 & 0.00 & 0.00 \\
\hline $\operatorname{corr}(\mathrm{P}, \mathrm{C})$ & 0.00 & 0.00 & 0.00 & 0.00 & 0.00 \\
\hline $\operatorname{corr}(P, q)$ & 0.00 & 0.00 & 0.00 & 0.00 & 0.00 \\
\hline $\operatorname{corr}(\mathrm{Q}, \mathrm{C})$ & 0.00 & 0.00 & 0.00 & 0.00 & 0.00 \\
\hline $\operatorname{corr}(\mathrm{Q}, \mathrm{q})$ & 0.20 & 0.40 & 0.60 & 0.80 & 1.00 \\
\hline $\operatorname{corr}(C, q)$ & 0.00 & 0.00 & 0.00 & 0.00 & 0.00 \\
\hline \multicolumn{6}{|c|}{ Section B: Outputs } \\
\hline $\mathrm{H}$ & -100.28 & -99.82 & -99.46 & -100.33 & -100.16 \\
\hline $\operatorname{var}(\mathrm{CFNH})$ & $4,455,902$ & $4,454,593$ & $4,437,262$ & $4,444,436$ & $4,441,094$ \\
\hline varOPT(CFH) & $2,196,520$ & $2,211,270$ & $2,196,427$ & $2,184,329$ & $2,196,698$ \\
\hline \%Efficiency & $50.71 \%$ & $50.36 \%$ & $50.50 \%$ & $50.85 \%$ & $50.54 \%$ \\
\hline
\end{tabular}

Table 1B Changing the correlation between $Q$ and $q$ if only weather derivatives are available

\begin{tabular}{lccccc}
\hline \multicolumn{5}{c}{ Section A: Inputs } \\
\hline Inputs & Scenario 1 & Scenario 2 & Scenario 3 & Scenario 4 & Scenario 5 \\
\hline $\mathrm{E}(\mathrm{P})$ & 100 & 100 & 100 & 100 & 100 \\
$\mathrm{E}(\mathrm{Q})$ & 100 & 100 & 100 & 100 & 100 \\
$\mathrm{E}(\mathrm{C})$ & 60 & 60 & 60 & 60 & 60 \\
$\mathrm{E}(\mathrm{q})$ & 0 & 0 & 0 & 0 & 0 \\
$\mathrm{SD}(\mathrm{P})$ & 15 & 15 & 15 & 15 & 15 \\
$\mathrm{SD}(\mathrm{Q})$ & 25 & 25 & 25 & 25 & 25 \\
$\mathrm{SD}(\mathrm{C})$ & 10 & 10 & 10 & 10 & 10 \\
\hline
\end{tabular}


Table 1B Changing the correlation between $Q$ and $q$ if only weather derivatives are available (continued)

\begin{tabular}{lccccc}
\hline \multicolumn{5}{c}{ Section A: Inputs } \\
\hline Inputs & Scenario 1 & Scenario 2 & Scenario 3 & Scenario 4 & Scenario 5 \\
\hline $\mathrm{SD}(\mathrm{q})$ & 1 & 1 & 1 & 1 & 1 \\
corr(P, Q) & 0.00 & 0.00 & 0.00 & 0.00 & 0.00 \\
corr(P, C) & 0.00 & 0.00 & 0.00 & 0.00 & 0.00 \\
$\operatorname{corr}(\mathrm{P}, \mathrm{q})$ & 0.00 & 0.00 & 0.00 & 0.00 & 0.00 \\
$\operatorname{corr}(\mathrm{Q}, \mathrm{C})$ & 0.00 & 0.00 & 0.00 & 0.00 & 0.00 \\
$\operatorname{corr}(\mathrm{Q}, \mathrm{q})$ & 0.20 & 0.40 & 0.60 & 0.80 & 1.00 \\
$\operatorname{corr}(\mathrm{C}, \mathrm{q})$ & 0.00 & 0.00 & 0.00 & 0.00 & 0.00 \\
\hline & & Section B: Outputs & & \\
\hline $\mathrm{G}$ & -210.24 & -421.85 & -617.42 & -815.89 & -995.85 \\
$\operatorname{var}(\mathrm{CFNH})$ & $4,455,902$ & $4,454,593$ & $4,437,262$ & $4,444,436$ & $4,441,094$ \\
$\operatorname{varOPT}(\mathrm{CFH})$ & $4,411,813$ & $4,277,212$ & $4,056,791$ & $3,783,278$ & $3,448,782$ \\
$\%$ Efficiency & $0.99 \%$ & $3.98 \%$ & $8.57 \%$ & $14.88 \%$ & $22.34 \%$ \\
\hline
\end{tabular}

Table 1C Changing the correlation between $\mathrm{Q}$ and $\mathrm{q}$ if both regular and weather derivatives are available

\begin{tabular}{|c|c|c|c|c|c|}
\hline \multicolumn{6}{|c|}{ Section A: Inputs } \\
\hline Inputs & Scenario 3 & Scenario 5 & Scenario 7 & Scenario 9 & Scenario 11 \\
\hline $\mathrm{E}(\mathrm{P})$ & 100 & 100 & 100 & 100 & 100 \\
\hline $\mathrm{E}(\mathrm{Q})$ & 100 & 100 & 100 & 100 & 100 \\
\hline $\mathrm{E}(\mathrm{C})$ & 60 & 60 & 60 & 60 & 60 \\
\hline$E(q)$ & 0 & 0 & 0 & 0 & 0 \\
\hline $\mathrm{SD}(\mathrm{P})$ & 15 & 15 & 15 & 15 & 15 \\
\hline $\mathrm{SD}(\mathrm{Q})$ & 25 & 25 & 25 & 25 & 25 \\
\hline $\mathrm{SD}(\mathrm{C})$ & 10 & 10 & 10 & 10 & 10 \\
\hline $\mathrm{SD}(\mathrm{q})$ & 1 & 1 & 1 & 1 & 1 \\
\hline $\operatorname{corr}(\mathrm{P}, \mathrm{Q})$ & 0.00 & 0.00 & 0.00 & 0.00 & 0.00 \\
\hline $\operatorname{corr}(\mathrm{P}, \mathrm{C})$ & 0.00 & 0.00 & 0.00 & 0.00 & 0.00 \\
\hline $\operatorname{corr}(P, q)$ & 0.00 & 0.00 & 0.00 & 0.00 & 0.00 \\
\hline $\operatorname{corr}(\mathrm{Q}, \mathrm{C})$ & 0.00 & 0.00 & 0.00 & 0.00 & 0.00 \\
\hline $\operatorname{corr}(\mathrm{Q}, \mathrm{q})$ & 0.20 & 0.40 & 0.60 & 0.80 & 1.00 \\
\hline $\operatorname{corr}(C, q)$ & 0.00 & 0.00 & 0.00 & 0.00 & 0.00 \\
\hline \multicolumn{6}{|c|}{ Section B: Outputs } \\
\hline $\mathrm{H}$ & -100.28 & -99.80 & -99.48 & -100.07 & -100.24 \\
\hline $\mathrm{G}$ & -210.10 & -421.02 & -618.13 & -808.63 & -997.60 \\
\hline $\operatorname{var}(\mathrm{CFNH})$ & $4,455,902$ & $4,454,593$ & $4,437,262$ & $4,444,436$ & $4,441,094$ \\
\hline varOPT(CFH) & $2,152,490$ & $2,034,584$ & $1,815,081$ & $1,534,904$ & $1,200,908$ \\
\hline$\%$ Efficiency & $51.69 \%$ & $54.33 \%$ & $59.09 \%$ & $65.46 \%$ & $72.96 \%$ \\
\hline
\end{tabular}


Tables $2 \mathrm{~A}$ to $2 \mathrm{C}$ show the result of applying the optimal hedging methodology to different scenarios where the standard deviation of $\tilde{Q}_{T}$ increases from 15 to 35 . The correlation between $\tilde{Q}_{T}$ and $\tilde{q}_{T}$ is assumed to be 0.8 . All the other stochastic variables (and in particular $\tilde{P}_{T}$ and $\tilde{Q}_{T}$ ) are assumed to be independent. The assumptions regarding volatility of the variables are described on each table.

Table 2A Changing the standard deviation of $Q$ if only regular derivatives a re available

\begin{tabular}{lccccc}
\hline \multicolumn{5}{c}{ Section A: inputs } \\
\hline Inputs & Scenario 1 & Scenario 2 & Scenario 3 & Scenario 4 & Scenario 5 \\
\hline $\mathrm{E}(\mathrm{P})$ & 100 & 100 & 100 & 100 & 100 \\
$\mathrm{E}(\mathrm{Q})$ & 100 & 100 & 100 & 100 & 100 \\
$\mathrm{E}(\mathrm{C})$ & 60 & 60 & 60 & 60 & 60 \\
$\mathrm{E}(\mathrm{q})$ & 0 & 0 & 0 & 0 & 0 \\
$\mathrm{SD}(\mathrm{P})$ & 15 & 15 & 15 & 15 & 15 \\
$\mathrm{SD}(\mathrm{Q})$ & 15 & 20 & 25 & 30 & 35 \\
$\mathrm{SD}(\mathrm{C})$ & 10 & 10 & 10 & 10 & 10 \\
$\mathrm{SD}(\mathrm{q})$ & 1 & 1 & 1 & 1 & 1 \\
corr(P, Q) & 0.00 & 0.00 & 0.00 & 0.00 & 0.00 \\
corr(P, C) & 0.00 & 0.00 & 0.00 & 0.00 & 0.00 \\
corr(P, q) & 0.00 & 0.00 & 0.00 & 0.00 & 0.00 \\
corr(Q, C) & 0.00 & 0.00 & 0.00 & 0.00 & 0.00 \\
corr(Q, q) & 0.80 & 0.80 & 0.80 & 0.80 & 0.80 \\
corr(C, q) & 0.00 & 0.00 & 0.00 & 0.00 & 0.00 \\
\hline & & Section B: outputs & & \\
\hline H & -100.16 & -100.22 & -100.33 & -100.24 & -100.76 \\
$\operatorname{var}(\mathrm{CFNH})$ & $3,709,989$ & $4,013,998$ & $4,444,436$ & $5,010,717$ & $5,641,123$ \\
$\operatorname{varOPT}(\mathrm{CFH})$ & $1,437,709$ & $1,771,165$ & $2,184,329$ & $2,735,846$ & $3,341,868$ \\
\%Efficiency & $61.25 \%$ & $55.88 \%$ & $50.85 \%$ & $45.40 \%$ & $40.76 \%$ \\
\hline
\end{tabular}

Table 2B Changing the standard deviation of $Q$ if only weather derivatives are available

\begin{tabular}{lccccc}
\hline \multicolumn{5}{c}{ Section A: inputs } \\
\hline Inputs & Scenario 1 & Scenario 2 & Scenario 3 & Scenario 4 & Scenario 5 \\
\hline $\mathrm{E}(\mathrm{P})$ & 100 & 100 & 100 & 100 & 100 \\
$\mathrm{E}(\mathrm{Q})$ & 100 & 100 & 100 & 100 & 100 \\
$\mathrm{E}(\mathrm{C})$ & 60 & 60 & 60 & 60 & 60 \\
$\mathrm{E}(\mathrm{q})$ & 0 & 0 & 0 & 0 & 0 \\
$\mathrm{SD}(\mathrm{P})$ & 15 & 15 & 15 & 15 & 15 \\
$\mathrm{SD}(\mathrm{Q})$ & 15 & 20 & 25 & 30 & 35 \\
$\mathrm{SD}(\mathrm{C})$ & 10 & 10 & 10 & 10 & 10 \\
\hline
\end{tabular}


Table 2B Changing the standard deviation of Q if only weather derivatives are available (continued)

\begin{tabular}{lccccc}
\hline \multicolumn{6}{c}{ Section A: inputs } \\
\hline Inputs & Scenario 1 & Scenario 2 & Scenario 3 & Scenario 4 & Scenario 5 \\
\hline $\mathrm{SD}(\mathrm{q})$ & 1 & 1 & 1 & 1 & 1 \\
corr(P, Q) & 0.00 & 0.00 & 0.00 & 0.00 & 0.00 \\
corr(P, C) & 0.00 & 0.00 & 0.00 & 0.00 & 0.00 \\
corr(P, q) & 0.00 & 0.00 & 0.00 & 0.00 & 0.00 \\
corr(Q, C) & 0.00 & 0.00 & 0.00 & 0.00 & 0.00 \\
$\operatorname{corr}(\mathrm{Q}, \mathrm{q})$ & 0.80 & 0.80 & 0.80 & 0.80 & 0.80 \\
corr(C, q) & 0.00 & 0.00 & 0.00 & 0.00 & 0.00 \\
\hline & & Section B: outputs & & \\
\hline G & -485.88 & -648.62 & -815.89 & -981.43 & $-1.141,07$ \\
$\operatorname{var}(\mathrm{CFNH})$ & $3,709,989$ & $4,013,998$ & $4,444,436$ & $5,010,717$ & $5,641,123$ \\
$\operatorname{varOPT}(\mathrm{CFH})$ & $3,473,468$ & $3,594,168$ & $3,783,278$ & $4,056,494$ & $4,334,482$ \\
$\%$ Efficiency & $6.38 \%$ & $10.46 \%$ & $14.88 \%$ & $19.04 \%$ & $23.16 \%$ \\
\hline
\end{tabular}

Table 2C Changing the standard deviation of $Q$ if both regular and weather derivatives a re available

\begin{tabular}{|c|c|c|c|c|c|}
\hline \multicolumn{6}{|c|}{ Section A: inputs } \\
\hline Inputs & Scenario 1 & Scenario 2 & Scenario 3 & Scenario 4 & Scenario 5 \\
\hline $\mathrm{E}(\mathrm{P})$ & 100 & 100 & 100 & 100 & 100 \\
\hline $\mathrm{E}(\mathrm{Q})$ & 100 & 100 & 100 & 100 & 100 \\
\hline $\mathrm{E}(\mathrm{C})$ & 60 & 60 & 60 & 60 & 60 \\
\hline$E(q)$ & 0 & 0 & 0 & 0 & 0 \\
\hline $\mathrm{SD}(\mathrm{P})$ & 15 & 15 & 15 & 15 & 15 \\
\hline $\mathrm{SD}(\mathrm{Q})$ & 15 & 20 & 25 & 30 & 35 \\
\hline $\mathrm{SD}(\mathrm{C})$ & 10 & 10 & 10 & 10 & 10 \\
\hline $\mathrm{SD}(\mathrm{q})$ & 1 & 1 & 1 & 1 & 1 \\
\hline $\operatorname{corr}(\mathrm{P}, \mathrm{Q})$ & 0.00 & 0.00 & 0.00 & 0.00 & 0.00 \\
\hline $\operatorname{corr}(\mathrm{P}, \mathrm{C})$ & 0.00 & 0.00 & 0.00 & 0.00 & 0.00 \\
\hline $\operatorname{corr}(P, q)$ & 0.00 & 0.00 & 0.00 & 0.00 & 0.00 \\
\hline $\operatorname{corr}(\mathrm{Q}, \mathrm{C})$ & 0.00 & 0.00 & 0.00 & 0.00 & 0.00 \\
\hline $\operatorname{corr}(\mathrm{Q}, \mathrm{q})$ & 0.80 & 0.80 & 0.80 & 0.80 & 0.80 \\
\hline $\operatorname{corr}(C, q)$ & 0.00 & 0.00 & 0.00 & 0.00 & 0.00 \\
\hline \multicolumn{6}{|c|}{ Section B: outputs } \\
\hline $\mathrm{H}$ & -100.22 & $-100,29$ & -100.07 & -100.12 & -100.46 \\
\hline $\mathrm{G}$ & -488.75 & $-651,07$ & -808.63 & -978.56 & $-1,135.23$ \\
\hline $\operatorname{var}(\mathrm{CFNH})$ & $3,709,989$ & $4,013,998$ & $4,444,436$ & $5,010,717$ & $5,641,123$ \\
\hline $\operatorname{varOPT}(\mathrm{CFH})$ & $1,198,388$ & $1,348,150$ & $1,534,904$ & $1,787,193$ & $2,048,576$ \\
\hline$\%$ Efficiency & $67.70 \%$ & $66.41 \%$ & $65.46 \%$ & $64.33 \%$ & $63.68 \%$ \\
\hline
\end{tabular}


Section B of Tables $2 \mathrm{~A}$ to $2 \mathrm{C}$ presents the results of the optimal hedging policies and maximum efficiency to be reached under each scenario. The quality of the hedging decreases as the volatility of $\tilde{Q}_{T}$ increases, when only regular derivatives are used. When only weather derivatives are available, the quality of the hedging increases as the standard deviation of $\tilde{Q}_{T}$ increases. If both derivatives are available, the quality of the hedging decreases slowly as the standard deviation of $\tilde{Q}_{T}$ increases. Regarding the hedging policies we appreciate how the hedging level in the regular derivative does not change across different standard deviations of $\tilde{Q}_{T}$, as could be predicted from our equation (20), and how the level in weather derivatives increases as the standard deviation of $\tilde{Q}_{T}$ increases, as could be deduced from our equation (21).

Tables $3 \mathrm{~A}$ to $3 \mathrm{C}$ show the result of applying the optimal hedging methodology to different scenarios where the standard deviation of $\tilde{P}_{T}$ increases from 5 to 25 . The correlation between $\tilde{Q}_{T}$ and $\tilde{q}_{T}$ is assumed to be 0.8 . All the other stochastic variables (and in particular $\tilde{P}_{T}$ and $\tilde{Q}_{T}$ ) are assumed to be independent. The assumptions regarding volatility of the variables are described on each table.

Table 3A Changing the standard deviation of $\mathrm{P}$ if only regular derivatives a re available

\begin{tabular}{|c|c|c|c|c|c|}
\hline \multicolumn{6}{|c|}{ Section A: inputs } \\
\hline Inputs & Scenario 1 & Scenario 2 & Scenario 3 & Scenario 4 & Scenario 5 \\
\hline $\mathrm{E}(\mathrm{P})$ & 100 & 100 & 100 & 100 & 100 \\
\hline $\mathrm{E}(\mathrm{Q})$ & 100 & 100 & 100 & 100 & 100 \\
\hline $\mathrm{E}(\mathrm{C})$ & 60 & 60 & 60 & 60 & 60 \\
\hline$E(q)$ & 0 & 0 & 0 & 0 & 0 \\
\hline $\mathrm{SD}(\mathrm{P})$ & 5 & 10 & 15 & 20 & 25 \\
\hline $\mathrm{SD}(\mathrm{Q})$ & 25 & 25 & 25 & 25 & 25 \\
\hline $\mathrm{SD}(\mathrm{C})$ & 10 & 10 & 10 & 10 & 10 \\
\hline $\mathrm{SD}(\mathrm{q})$ & 1 & 1 & 1 & 1 & 1 \\
\hline $\operatorname{corr}(\mathrm{P}, \mathrm{Q})$ & 0.00 & 0.00 & 0.00 & 0.00 & 0.00 \\
\hline $\operatorname{corr}(\mathrm{P}, \mathrm{C})$ & 0.00 & 0.00 & 0.00 & 0.00 & 0.00 \\
\hline $\operatorname{corr}(P, q)$ & 0.00 & 0.00 & 0.00 & 0.00 & 0.00 \\
\hline $\operatorname{corr}(\mathrm{Q}, \mathrm{C})$ & 0.00 & 0.00 & 0.00 & 0.00 & 0.00 \\
\hline $\operatorname{corr}(\mathrm{Q}, \mathrm{q})$ & 0.80 & 0.80 & 0.80 & 0.80 & 0.80 \\
\hline $\operatorname{corr}(C, q)$ & 0.00 & 0.00 & 0.00 & 0.00 & 0.00 \\
\hline \multicolumn{6}{|c|}{ Section B: outputs } \\
\hline $\mathrm{H}$ & -101.19 & -100.43 & -100.33 & -100.03 & -99.85 \\
\hline $\operatorname{var}(\mathrm{CFNH})$ & $2,328,243$ & $3,136,339$ & $4,444,436$ & $6,321,986$ & $8,731,012$ \\
\hline varOPT(CFH) & $2,071,810$ & $2,133,109$ & $2,184,329$ & $2,314,204$ & $2,467,469$ \\
\hline \%Efficiency & $11.01 \%$ & $31.99 \%$ & $50.85 \%$ & $63.39 \%$ & $71.74 \%$ \\
\hline
\end{tabular}


Table 3B Changing the standard deviation of $\mathrm{P}$ if only weather derivatives a re available

\begin{tabular}{lccccc}
\hline \multicolumn{5}{c}{ Section A: inputs } \\
\hline Inputs & Scenario 1 & Scenario 2 & Scenario 3 & Scenario 4 & Scenario 5 \\
\hline $\mathrm{E}(\mathrm{P})$ & 100 & 100 & 100 & 100 & 100 \\
$\mathrm{E}(\mathrm{Q})$ & 100 & 100 & 100 & 100 & 100 \\
$\mathrm{E}(\mathrm{C})$ & 60 & 60 & 60 & 60 & 60 \\
$\mathrm{E}(\mathrm{q})$ & 0 & 0 & 0 & 0 & 0 \\
$\mathrm{SD}(\mathrm{P})$ & 5 & 10 & 15 & 20 & 25 \\
$\mathrm{SD}(\mathrm{Q})$ & 25 & 25 & 25 & 25 & 25 \\
$\mathrm{SD}(\mathrm{C})$ & 10 & 10 & 10 & 10 & 10 \\
$\mathrm{SD}(\mathrm{q})$ & 1 & 1 & 1 & 1 & 1 \\
corr(P, Q) & 0.00 & 0.00 & 0.00 & 0.00 & 0.00 \\
corr(P, C) & 0.00 & 0.00 & 0.00 & 0.00 & 0.00 \\
corr(P, q) & 0.00 & 0.00 & 0.00 & 0.00 & 0.00 \\
corr(Q, C) & 0.00 & 0.00 & 0.00 & 0.00 & 0.00 \\
corr(Q, q) & 0.80 & 0.80 & 0.80 & 0.80 & 0.80 \\
corr(C, q) & 0.00 & 0.00 & 0.00 & 0.00 & 0.00 \\
\hline & & Section B: outputs & & \\
\hline G & -812.90 & -818.79 & -815.89 & -820.15 & -832.28 \\
$\operatorname{var}(\mathrm{CFNH})$ & $2,328,243$ & $3,136,339$ & $4,444,436$ & $6,321,986$ & $8,731,012$ \\
$\operatorname{varOPT}(\mathrm{CFH})$ & $1,670,098$ & $2,463,186$ & $3,783,278$ & $5,653,977$ & $8,035,699$ \\
\%Efficiency & $28.27 \%$ & $21.46 \%$ & $14.88 \%$ & $10.57 \%$ & $7.96 \%$ \\
\hline Table 3C & & & & & \\
\hline
\end{tabular}

Table 3C Changing the standard deviation of P If both regular and weather derivatives are available

\begin{tabular}{lccccc}
\hline \multicolumn{5}{c}{ Section A: inputs } \\
\hline Inputs & Scenario 1 & Scenario 2 & Scenario 3 & Scenario 4 & Scenario 5 \\
\hline $\mathrm{E}(\mathrm{P})$ & 100 & 100 & 100 & 100 & 100 \\
$\mathrm{E}(\mathrm{Q})$ & 100 & 100 & 100 & 100 & 100 \\
$\mathrm{E}(\mathrm{C})$ & 60 & 60 & 60 & 60 & 60 \\
$\mathrm{E}(\mathrm{q})$ & 0 & 0 & 0 & 0 & 0 \\
$\mathrm{SD}(\mathrm{P})$ & 5 & 10 & 15 & 20 & 25 \\
$\mathrm{SD}(\mathrm{Q})$ & 25 & 25 & 25 & 25 & 25 \\
$\mathrm{SD}(\mathrm{C})$ & 10 & 10 & 10 & 10 & 10 \\
$\mathrm{SD}(\mathrm{q})$ & 1 & 1 & 1 & 1 & 1 \\
$\operatorname{corr}(\mathrm{P}, \mathrm{Q})$ & 0.00 & 0.00 & 0.00 & 0.00 & 0.00 \\
$\operatorname{corr}(\mathrm{P}, \mathrm{C})$ & 0.00 & 0.00 & 0.00 & 0.00 & 0.00 \\
$\operatorname{corr}(\mathrm{P}, \mathrm{q})$ & 0.00 & 0.00 & 0.00 & 0.00 & 0.00 \\
$\operatorname{corr}(\mathrm{Q}, \mathrm{C})$ & 0.00 & 0.00 & 0.00 & 0.00 & 0.00 \\
$\operatorname{cor}(\mathrm{Q}, \mathrm{q})$ & 0.80 & 0.80 & 0.80 & 0.80 & 0.80 \\
$\operatorname{corr}(\mathrm{C}, \mathrm{q})$ & 0.00 & 0.00 & 0.00 & 0.00 & 0.00 \\
\hline
\end{tabular}


Table 3C Changing the standard deviation of P If both regular and weather derivatives are available (continued)

\begin{tabular}{lccccc}
\hline \multicolumn{5}{c}{ Section B: outputs } \\
\hline $\mathrm{H}$ & -100.45 & -100.27 & -100.07 & -99.92 & -99.72 \\
$\mathrm{G}$ & -810.61 & -816.87 & -808.63 & -814.93 & -822.35 \\
$\operatorname{var}(\mathrm{CFNH})$ & $2,328,243$ & $3,136,339$ & $4,444,436$ & $6,321,986$ & $8,731,012$ \\
$\operatorname{varOPT}(\mathrm{CFH})$ & $1,417,377$ & $1,463,111$ & $1,534,904$ & $1,654,686$ & $1,788,665$ \\
$\%$ Efficiency & $39.12 \%$ & $53.35 \%$ & $65.46 \%$ & $73.83 \%$ & $79.51 \%$ \\
\hline
\end{tabular}

Section $\mathrm{B}$ of Tables $3 \mathrm{~A}$ to $3 \mathrm{C}$ presents the results of the optimal hedging policies and maximum efficiency to be reached under each scenario. The quality of the hedging increases as the volatility of $\tilde{P}_{T}$ increases, when only regular derivatives are used. When only weather derivatives are available, the quality of the hedging decreases as the standard deviation of $\tilde{P}_{T}$ increases. If both derivatives are used, the quality of the hedging increases as the standard deviation of $\tilde{P}_{T}$ increases. Regarding the hedging policies we appreciate how the level of the optimal hedging policies in both the regular derivativeand also the weather derivative do not change as the standard deviation of $\tilde{P}_{T}$ increases, reflecting the fact that the volatility of that variable is not relevant, as can be appreciated in equations (20) and (21).

\subsection{Recognising that $P$ and $Q$ can be correlated}

In this section, we compare the results of the previous section, allowing now for the existence of correlation (negative or positive) between price and quantity. It is very uncommon to find examples in real life of prices and quantities that do not correlate. As we show in this section, recognising the true correlation between these two variables has an impact not only in the quality of the optimal hedging that can be reached, but also in the level of those hedging policies, in particular in the level of the hedging policies that should be applied when using regular derivatives.

Figure 1A Efficiency and correlation between production level Q and the weather variable $q$

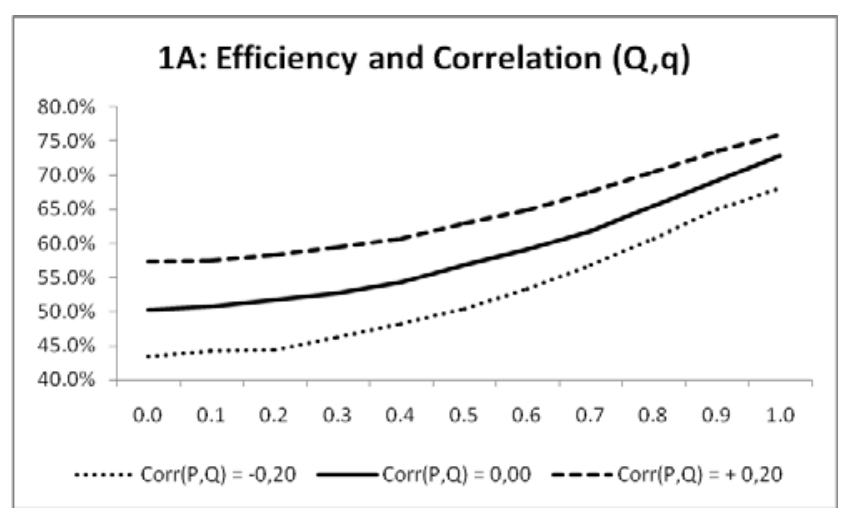


Figure 1B Efficiency level and standard deviation of production Q

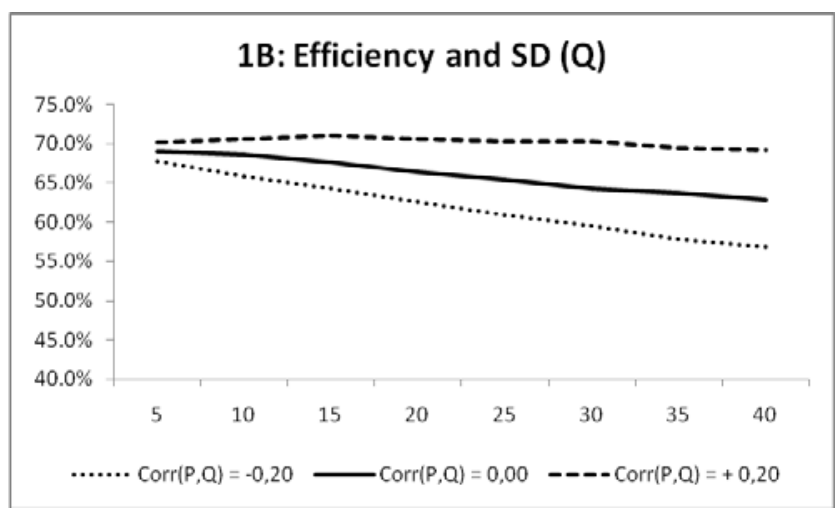

Figure 1C Efficiency level and standard deviation of product price $\mathrm{P}$

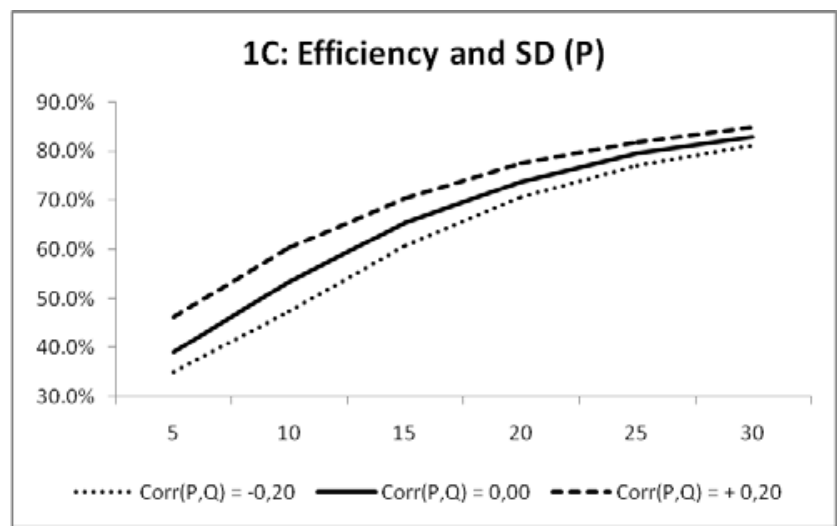

Figure 1A shows how the quality of the hedging changes as we change the correlation between $\tilde{Q}_{T}$ and $\tilde{q}_{T}$ if correlation between $\tilde{P}_{T}$ and $\tilde{Q}_{T}$ is -0.2 or 0.0 or +0.2 . We conclude that a positive correlation between $\tilde{P}_{T}$ and $\tilde{Q}_{T}$ increases the quality of the correlation for all the possible values of the correlation of $\tilde{Q}_{T}$ and $\tilde{q}_{T}$. We also conclude that a negative correlation between $\tilde{P}_{T}$ and $\tilde{Q}_{T}$ has the opposite effect. Figure 1B shows how the quality of the hedging changes as we change the standard deviation of $\tilde{Q}_{T}$, if correlation between $\tilde{P}_{T}$ and $\tilde{Q}_{T}$ is -0.2 or 0.0 or +0.2 . We conclude that a positive correlation between $\tilde{P}_{T}$ and $\tilde{Q}_{T}$ increases the quality of the correlation for all the possible values of the standard deviation of $\tilde{Q}_{T}$. We also conclude that a negative correlation between $\tilde{P}_{T}$ and $\tilde{Q}_{T}$ has the opposite effect. Figure 1C shows how the quality of the hedging changes as we change the standard deviation of $\tilde{P}_{T}$, if correlation between $\tilde{P}_{T}$ and $\tilde{Q}_{T}$ is -0.2 or 0.0 or +0.2 . We conclude that a positive correlation between $\tilde{P}_{T}$ and $\tilde{Q}_{T}$ increases the quality of the correlation for all the possible values of the standard 
deviation of $\tilde{P}_{T}$. We also conclude that a negative correlation between $\tilde{P}_{T}$ and $\tilde{Q}_{T}$ has the opposite effect.

Figure 2A Optimal hedging ratio $\mathrm{H}$ and the correlation between production level $\mathrm{Q}$ and the weather variable $\mathrm{q}$

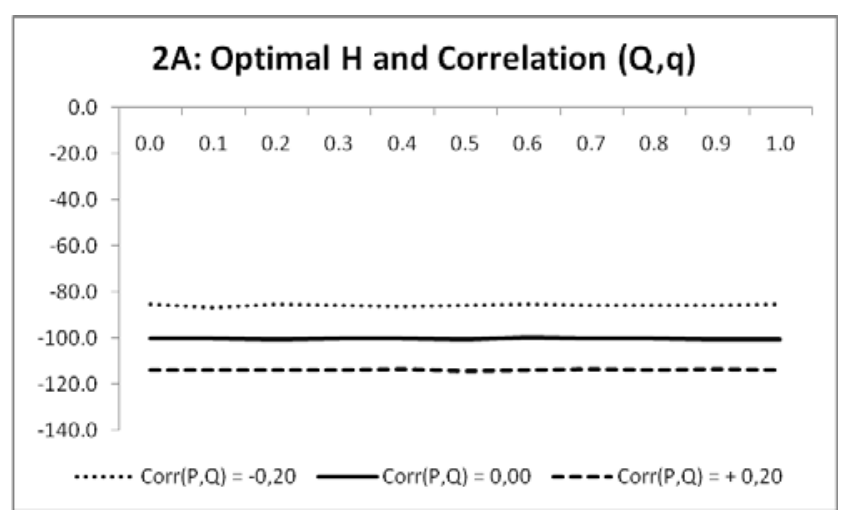

Figure 2B Optimal hedging ratio $\mathrm{H}$ and the standard deviation of production level $\mathrm{Q}$

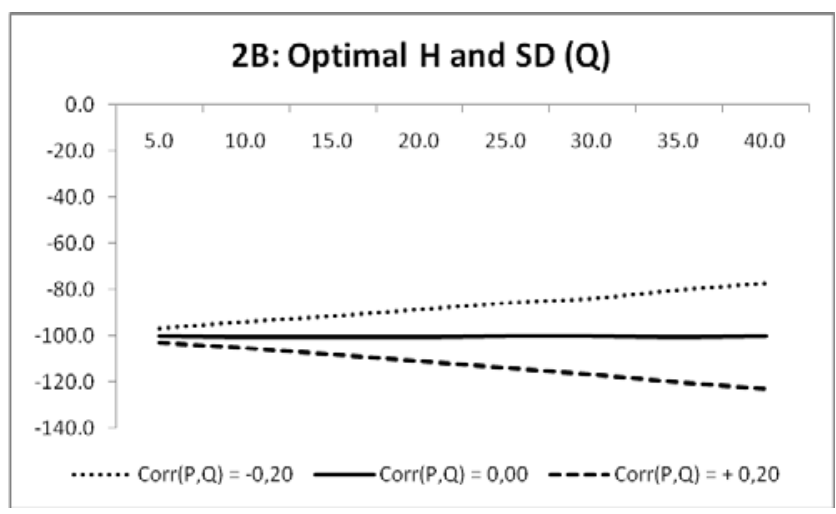

Figure 2C Optimal hedging ratio $\mathrm{H}$ and the standard deviation of product price $\mathrm{P}$

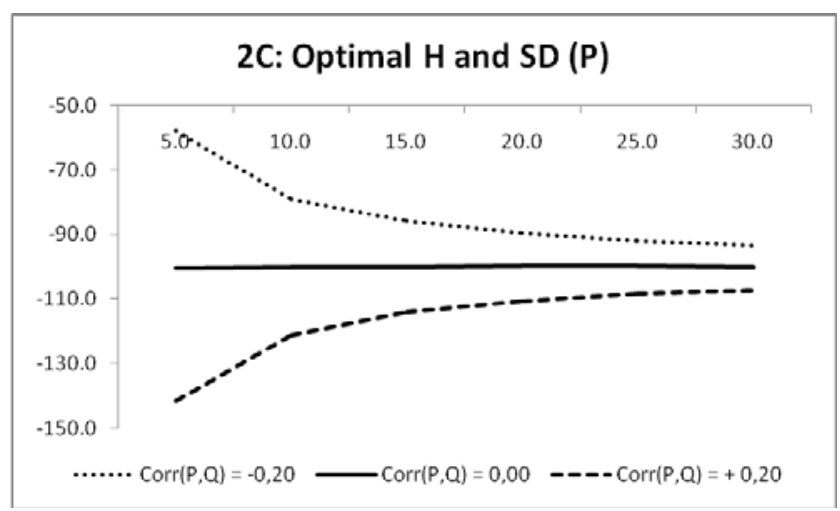


Figure 2A shows how the optimal hedging in the regular derivative $\mathrm{H}$ changes as we change the correlation between $\tilde{Q}_{T}$ and $\tilde{q}_{T}$, if correlation between $\tilde{P}_{T}$ and $\tilde{Q}_{T}$ is -0.2 or 0.0 or +0.2 . We conclude that a positive correlation between $\tilde{P}_{T}$ and $\tilde{Q}_{T}$ reduces the number of short positions to be taken for all the possible values of the correlation of $\tilde{Q}_{T}$ and $\tilde{q}_{T}$. We also conclude that a negative correlation between $\tilde{P}_{T}$ and $\tilde{Q}_{T}$ has the opposite effect. In all the cases, $\mathrm{H}$ does not change when we change correlation between $\tilde{Q}_{T}$ and $\tilde{q}_{T}$. Figure $2 \mathrm{~B}$ shows how the optimal hedging in the regular derivative $\mathrm{H}$ changes as we change the standard deviation of $\tilde{Q}_{T}$, if correlation between $\tilde{P}_{T}$ and $\tilde{Q}_{T}$ is -0.2 or 0.0 or +0.2 . We conclude that a positive correlation between $\tilde{P}_{T}$ and $\tilde{Q}_{T}$ reduces the number of short positions to be taken for all the possible values of the standard deviation of $\tilde{Q}_{T}$, but we also conclude that $\mathrm{H}$ decreases as the standard deviation of $\tilde{Q}_{T}$ increases. If the correlation between $\tilde{P}_{T}$ and $\tilde{Q}_{T}$ is negative, we observe an increase in the number of short positions to be taken, for all the possible values of the standard deviation of $\tilde{Q}_{T}$, but we also conclude that $\mathrm{H}$ increases as the standard deviation of $\tilde{Q}_{T}$ increases. Figure $2 \mathrm{C}$ shows how the optimal hedging in the regular derivative $\mathrm{H}$ changes as we change the standard deviation of $\tilde{P}_{T}$, if correlation between $\tilde{P}_{T}$ and $\tilde{Q}_{T}$ is -0.2 or 0.0 or +0.2 . We conclude that a positive correlation between $\tilde{P}_{T}$ and $\tilde{Q}_{T}$ increases the number of short positions to be taken for all the possible values of the standard deviation of $\tilde{P}_{T}$, but we also conclude that $\mathrm{H}$ decreases as the standard deviation of $\tilde{P}_{T}$ increases. If the correlation between $\tilde{P}_{T}$ and $\tilde{Q}_{T}$ is negative, we observe a decrease in the number of short positions to be taken, for all the possible values of the standard deviation of $\tilde{P}_{T}$, but we also conclude that $\mathrm{H}$ increases as the standard deviation of $\tilde{P}_{T}$ increases.

Figure 3A Optimal hedging ratio $\mathrm{G}$ and the correlation between production level $\mathrm{Q}$ and the weather variable $\mathrm{q}$

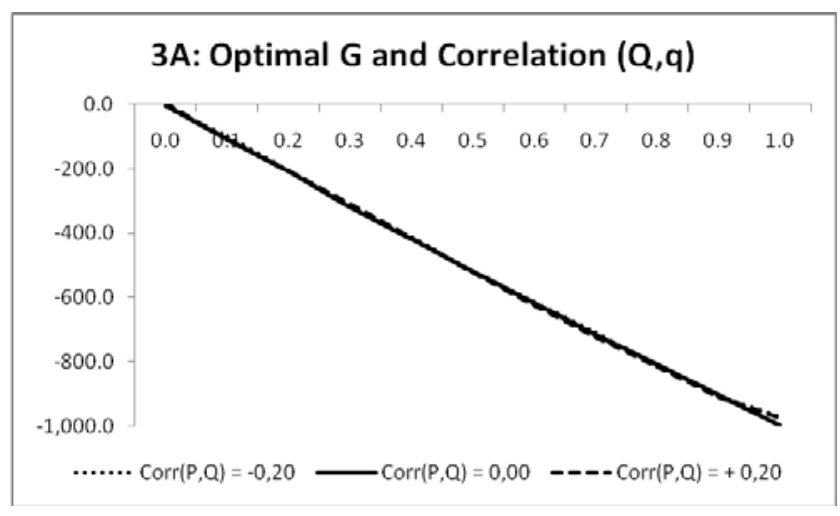


Figure 3B Optimal hedging ratio $\mathrm{G}$ and the standard deviation of production level $\mathrm{Q}$

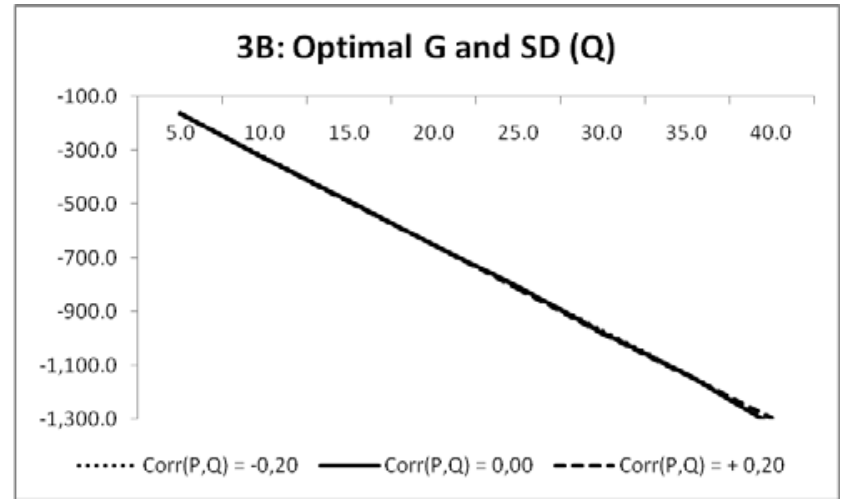

Figure 3C Optimal hedging ratio $\mathrm{G}$ and the standard deviation of product price $\mathrm{P}$

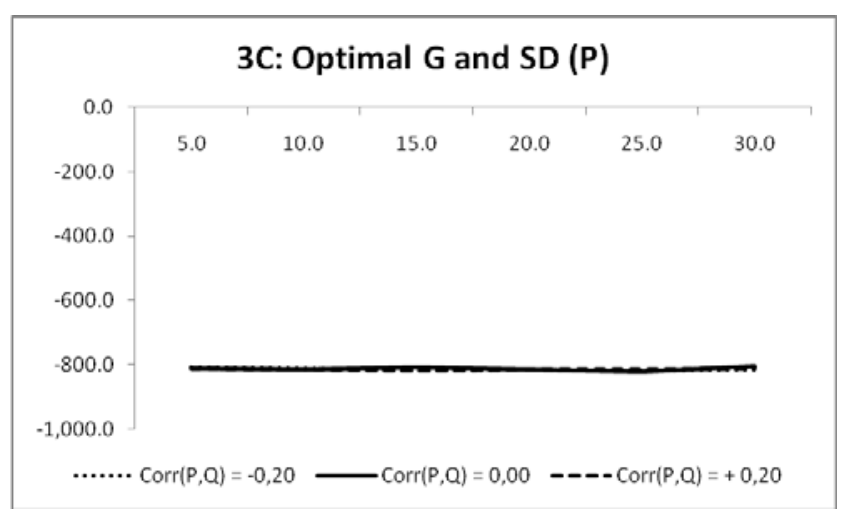

Figure $3 \mathrm{~A}$ shows how the optimal hedging in the weather derivative $\mathrm{G}$ changes as we change the correlation between $\tilde{Q}_{T}$ and $\tilde{q}_{T}$, if correlation between $\tilde{P}_{T}$ and $\tilde{Q}_{T}$ is -0.2 or 0.0 or +0.2 . The figure suggests that the degree of correlation between $\tilde{P}_{T}$ and $\tilde{Q}_{T}$ has no significant impact on $\mathrm{G}$. The number of positions in weather derivatives increases with the degree of correlation between $\tilde{Q}_{T}$ and $\tilde{q}_{T}$. Figure 3B shows how the optimal hedging in the weather derivative $\mathrm{G}$ changes as we change the standard deviation of $\tilde{Q}_{T}$, if correlation between $\tilde{P}_{T}$ and $\tilde{Q}_{T}$ is -0.2 or 0.0 or +0.2 . The figure suggests that the degree of correlation between $\tilde{P}_{T}$ and $\tilde{Q}_{T}$ has no significant impact on G. The number of positions in weather derivatives increases with the standard deviation of $\tilde{Q}_{T}$. Figure $3 \mathrm{C}$ shows how the optimal hedging in the weather derivative $\mathrm{G}$ changes as we change the standard deviation of $\tilde{P}_{T}$, if correlation between $\tilde{P}_{T}$ and $\tilde{Q}_{T}$ is -0.2 or 0.0 or +0.2 . The figure suggests that the degree of correlation between $\tilde{P}_{T}$ and $\tilde{Q}_{T}$ has no significant impact on $G$. The number of positions in weather derivatives in all cases shows no relationship with the standard deviation of $\tilde{P}_{T}$. 


\section{Summary and conclusions}

This study analyses how to achieve the optimal hedging of a cash flow to be received at a future date $\mathrm{T}$, when facing price risk if we are also in the presence of cost and quantity uncertainty. We explore and compare the case where the only instrument available to hedge is a regular forward contract (to hedge the price uncertainty), the case where we only have access to a linear-type weather derivative to hedge quantity, and the case where we have access to both types of derivatives. Obviously the use of weather derivatives to improve the hedging of the cash flow of a company would only make sense in a company where its cash flow is correlated to a weather variable that is considered by a particular weather derivative.

A closed form solution for both the optimal hedging strategies and the quality of the hedging under each scenario are identified. We also show how to obtain the optimal hedging strategies through linear regressions, and how the quality of the optimal hedging strategy is measured by the determination coefficient $\left(\mathrm{R}^{2}\right)$ of the same regression. The closed form solutions found allow us to explore how the different parameters considered here, such as the volatilities of all the stochastic variables considered or the degree of correlation among them would impact both the optimal hedging policies and the quality of the optimal hedging solution.

Section 3 shows an example where the optimal hedging strategies and the quality of the hedging are computed for different scenarios. Then it is explored how the results critically depend on some key factors such as the volatility of some stochastic variables such as $\tilde{P}_{T}$ and $\tilde{Q}_{T}$ and on some key correlations such as the ones between $\tilde{Q}_{T}$ and $\tilde{q}_{T}$ or between $\tilde{P}_{T}$ and $\tilde{Q}_{T}$. The example allows to verify for example how the optimal hedging solutions can deviate from the simple hedging strategies derived when no correlation between $\tilde{P}_{T}$ and $\tilde{Q}_{T}$ is considered.

\section{References}

Basak, S. and Chabakauri, G. (2012) 'Dynamic hedging in incomplete markets: a simple solution', Review of Financial Studies, pp.1-52 [online] http://ssrn.com/abstract=1297182 (accessed 13 April 2012).

Bessembinder, H. (1991) 'Forward contracts and firm value', Journal of Financial and Quantitative Analysis, Vol. 17, No. 4, pp.519-572.

Brennan, M.J. and Crew, N. (1997) 'Hedging long maturity commodity commitments with short dated futures contracts', Mathematics of Derivative Securities, pp.165-190, Cambridge University Press, New York.

Broll, U., Wahl, J.E. and Zilcha, I. (1999) 'Hedging exchange rate risk: the multiperiod case', Research in Economics, Vol. 53, No. 4, pp.365-380.

Castillo, A. and Aguila, R. (2008) 'Cobertura Optima de Riesgos de Mercado en Presencia de Riesgos de Cantidad y de Costos de Producción', El Trimestre Económico, Vol. 75, No. 299, pp.755-778.

Castillo, A. and Lefort, F. (2003) 'Protección Contra la Exposición del Tipo de Cambio a Largo Plazo con Contratos de Futuros a Corto Plazo: El Caso de los Contratos Forward en UF chilenas/dólares', El Trimestre Económico, Vol. 70, No. 279, pp.423-456. 
Castillo, A., Aguila, R. and Niño, J. (2012) 'Long term exchange rate risk and hedging with quantity uncertainty in a market that only provides short term futures contracts', Academia, Vol. 50, No. 50, pp.66-78.

Duffie, D. (1989) Futures Markets, Prentice Hall, New York .

Frestad, D. (2009) 'Why most firms choose linear hedging strategies', Journal of Financial Research, Vol. 32, No. 2, pp.157-167.

Froot, K.A., Scharfstein, D.S. and Stein, J.C. (1993) 'Risk management: coordinating corporate investment and risk management policies', Journal of Finance, Vol. 48, No. 5, pp.1629-1658.

Golden, L., Wang, M. and Yang, C. (2007) 'Handling weather related risks through the financial markets: considerations of credit risk, basis risk, and hedging', The Journal of Risk and Insurance, Vol. 74, No. 2, pp.319-346.

Hull, J.C. (2008) Options, Futures and Other Derivatives, 7th ed., Prentice Hall, Upper Saddle River, New Jersey.

Kamgaing, M.C. (1989) 'Optimal hedging under price, quantity and exchange rate uncertainty', African Development Review, Vol. 1, No. 2, pp.108-124.

Kerkvliet, J. and Moffett, M.H. (1991) 'The hedging of an uncertain future foreign currency cash flow', Journal of Financial and Quantitative Analysis, Vol. 26, No. 4, pp.565-578.

Korn, O. (2010) 'How firms should hedge: an extension', The Journal of Futures Markets, Vol. 30, No. 9, pp.834-845.

Manfredo, M.R. and Richards, T.J. (2009) 'Hedging with weather derivatives: a role for options in reducing basis risk', Applied Financial Economics, Vol. 19, No. 2, pp.87-97.

Mello, A. and Parsons, J. (1995) 'Maturity structure of a hedge matters: lessons from the Metallgesellschaft Debacle', Journal of Applied Corporate Finance, Vol. 8, No. 1, pp.106-120.

Moschini, G. and Lapan, H. (1995) 'The hedging role of options and futures under joint price, basis and production risks', International Economic Review, Vol. 36, No. 4, pp.1025-1049.

Näsäkkälä, E. and Keppo, J. (2005) 'Electricity load pattern hedging with static forward strategies', Managerial Finance, Vol. 31, No. 6, pp.116-137.

Neuberger, A. (1999) 'Hedging long term exposures with multiple short-term futures contracts', The Review of Financial Studies, Fall, Vol. 12, No. 3, pp.429-459.

Newbery, D. and Stiglitz, J. (1981) The Theory of Commodity Price Stabilization: A Study in the Economics of Risk, Oxford Press, Claredon.

Oum, Y. and Orem, S.S. (2010) 'Optimal static hedging of volumetric risk in a competitive wholesale electricity market', Decision Analysis, Vol. 7, No. 1, pp.107-122.

Richards, T.J., Manfredo, M.R. and Sanders, D.R. (2004) 'Pricing weather derivatives', American Journal of Agricultural Economy, Vol. 86, No. 4, pp.1005-1017.

Rolfo, J. (1980) 'Optimal hedging under price and quantity uncertainty: the case of a cocoa producer', Journal of Political Economy, Vol. 88, No. 1, pp.100-116.

Schwartz, E.S. (1997) 'Presidential address: the stochastic behavior of commodity prices: implications for valuation and hedging', Journal of Finance, Vol. 52, No. 3, pp.923-973.

Smith, C.W. and Stulz, R.M. (1985) 'The determinants of firm's hedging policies', Journal of Financial and Quantitative Analysis, Vol. 20, No. 4, pp.391-405.

Stulz, R.M. (2003) Risk Management and Derivatives, 1st ed., South Western College Publishing, Cincinnati OH, USA.

Torriani, D.S., Calanca, P., Beniston, M. and Fuhrer, J. (2008) 'Hedging with weather derivatives to cope with climate variability and change in grain maize production', Agricultural Finance Review, Vol. 68, No. 1, pp.67-81.

Wong, K.P. (2003) 'Currency hedging with options and futures', European Economic Review, Vol. 47, No. 5, pp.833-839. 


\section{Notes}

1 Imagine that you want to hedge the price of a stock and the only futures contract available defines a related stock index as its underlying asset. Or as in this paper, imagine you want to hedge a certain agricultural production level and the derivative contract available relates to rain precipitations on that geographical location.

2 All the results presented in this section are the consequence of generating sets of 100.000 random numbers with the required characteristics for each scenario. For simplicity it is assumed that all the variables follow a normal distribution. 